Int. J. Electrochem. Sci., 12 (2017) 4597 - 4609

\title{
Carbon Nanofibers Decorated with Pt-Co Alloy Nanoparticles as Catalysts for Electrochemical Cell Applications. I. Synthesis and Structural Characterization
}

\author{
Roxana Muntean ${ }^{1,2}$, Dragoș-Toader Pascal ${ }^{1,2}$, Gabriela Mărginean ${ }^{2}$, Nicolae Vaszilcsin $^{1, *}$ \\ ${ }^{1}$ Faculty of Industrial Chemistry and Environmental Engineering, Politehnica University Timișoara, \\ 300006 Piața Victoriei 2, Timișoara, Romania \\ ${ }^{2}$ Department of Materials Science and Testing, Westphalian University of Applied Sciences, \\ Neidenburger Str. 4345897, Gelsenkirchen, Germany \\ *E-mail: nicolae.vaszilcsin@upt.ro
}

doi: $10.20964 / 2017.05 .25$

Received: 7 September 2016 / Accepted: 17 February 2017 / Published: 12 April 2017

Pt-Co alloy deposition on carbon nanofibers (CNF) is achieved using an electrochemical method: pulsed plating current technique. In order to improve the hydrophilic properties of fibers, to achieve a better dispersion of the catalyst particles, $\mathrm{CNF}$ were previously functionalized using oxygen plasma treatment. The optimization of the deposition parameters has been performed by linear and cyclic voltammetry, varying the concentration ratio between $\mathrm{Pt}^{2+}$ and $\mathrm{Co}^{2+}$ in the electrolyte. Obtained samples were characterized using scanning electron microscopy combined with energy dispersive Xray spectroscopy in respect to their structure and chemical composition, as well as X-ray diffraction for Pt-Co alloy phase identification. The amount of catalyst found onto the substrate material after the deposition process has been determined using thermogravimetric analyses and the Pt-Co ratios in the alloy were checked with X-ray fluorescence spectroscopy. The electrochemical surface area was measured using cyclic voltammograms plotted in $\mathrm{H}_{2} \mathrm{SO}_{4} 0.5 \mathrm{M}$ solution. It was found that, employing this electrochemical method and applying the selected deposition parameters, beside the pure $\mathrm{Pt}$ particles, a rich Pt-Co alloy phase is formed, namely $\mathrm{CoPt}_{3}$. The amount of $\mathrm{CoPt}_{3}$ varies with the increase of Co content in the deposition bath. The obtained electrodes show a high surface area which may be attributed to structural changes achieved by alloying process, combined with the large surface area of the CNF employed as support.

Keywords: Pt-Co electrodeposition, Carbon nanofibers, Oxygen plasma activation, Electrocatalysts 
(C) 2017 The Authors. Published by ESG (www.electrochemsci.org). This article is an open access article distributed under the terms and conditions of the Creative Commons Attribution license (http://creativecommons.org/licenses/by/4.0/). 